\title{
Accuracy of clinical fetal weight estimation by Midwives
}

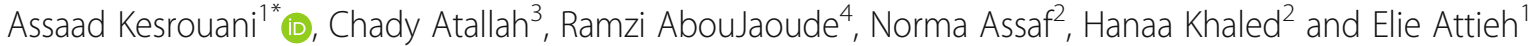

\begin{abstract}
Background: Clinical fetal weight estimation is a common practice in obstetrics. This study aims to evaluate the accuracy of fetal weight estimation by midwives, and to identify factors that may lead to overestimation or underestimation of fetal weight.

Methods: A cohort prospective study in a Lebanese university hospital, included weight estimation of singleton pregnancies above 35 weeks. Multiple pregnancies, unclear dating, growth retardation, malformations and stillbirths cases are excluded. The estimated fetal weight is recorded by midwives in a sealed envelope and compared to true weight later. The effects of BMI, weight gain, parity, diabetes, hypertension, neonate's sex and weight, uterine contractions, rupture of membranes and daytime or nighttime shift on these estimations were assessed.

Results: One hundred and sixty-six patients were included. Mean birth weight was $3246 \pm 362 \mathrm{~g}$. Mean absolute percentage error of weight estimation was $8.5 \pm 6.7 \%$ (0-30.9\%). Estimation was within the correct range of $\pm 10 \%$ in $63 \%$ of cases. Maternal and fetal factors did not significantly change weight estimation. Fetuses with birth weights more than 4000 tended to be underestimated by midwives. Estimation improved over time (nonsignificant).
\end{abstract}

Conclusions: Maternal and fetal factors, except for macrosomia, have limited impact on estimation of fetal birth weight. Macrosomia is challenging because of a consistent tendency of underestimation by midwives.

Keywords: Estimation, Fetal weight, Clinical, Midwife

\section{Background}

Accurate estimation of fetal weight in late pregnancy provides valuable information for decision making in the management of birth, namely the mode and time of birth, as well as the subsequent management of the mother and the neonate [1]. This is especially true for fetuses at the extremes of birth weight, low birth weight and macrosomia [2]. Neonates with weights below the third percentile have a higher risk than the general population for developing neonatal respiratory distress syndrome, intraventricular hemorrhage and necrotizing enterocolitis during the perinatal period [3]. On the other hand, fetal macrosomia is associated with more maternal and fetal complications at the time of birth than other neonatal weight groups [4]. Maternal complications include increased cesarean rate, higher risk of injury to the genital tract, uterine rupture, as well as

\footnotetext{
* Correspondence: drkesrouani@gmail.com

'Ob-Gyn Department, St Joseph University, Adib Ishac St, Achrafie, Beirut, Lebanon

Full list of author information is available at the end of the article
}

post-partum hemorrhage [5], while fetal complications include a higher risk for shoulder dystocia that could lead to bone fractures and permanent damage to the brachial plexus $[1,6-8]$. The perinatal mortality rate and the rate of admission to the pediatric intensive care are also higher for neonates with macrosomia [5]. Correlation between estimated and true weight is variable among studies [9].

The purpose of this study is to evaluate the accuracy of the estimated fetal weight performed during labor by midwives at the Obstetrics and Gynecology department of a University Hospital in Beirut and to evaluate maternal and fetal factors that might affect the variation of this estimation.

\section{Methods}

A prospective cohort study data collection included 166 parturients who delivered at Hotel-Dieu de France University Hospital, Beirut, from November 2010 to March 2011. Both last menstrual period and ultrasound 
were used to set the correct dating of pregnancies. The inclusion criteria were: a viable fetus of above 35 weeks, a singleton pregnancy and admission for labor and birth. Exclusion criteria consisted of the following: cases complicated by growth retardation, pregnancies with an unclear expected delivery date, multiple pregnancies, congenital malformations of the fetus, and stillbirths. The study is approved and registered by our institution's review board under the number CEHDF-919.

Oral consent of participants was mandatory after explaining the potential scientific benefits and the absence of harm to the mother and her baby. A clinical estimation of the fetal weight by bimanual abdominal palpation (Leopold-Pavlik maneuver) was performed the midwife who was on duty $(n=4)$. Weight estimation was done when the patient was admitted to the hospital for delivery, with or without labor. The four midwives involved in this study are considered experienced and of equal obstetrical skills for initial evaluation of parturients as they have spent at least 2 years in the birth ward.

The result was dated and placed in a sealed envelope that was put in a closed box. At the end of the study, the box was opened for data retrieval and analysis. In order to avoid biased results, these estimations were made individually; the midwife did not have access to the patient's chart or the prenatal records prior to weight estimation and no information was disclosed regarding the last estimated fetal weight by ultrasound they had at the doctor's office.

The gold standard for comparing estimated fetal weight was the real birth weight, which was obtained immediately after birth using a digital scale. Analysis of the accuracy of fetal weight estimation was performed using the percent error \{(estimated weight-actual weight)* 100 /actual weight\}. However, this formula has an inherent limitation because positive deviations from the real weight cancel the negative ones leading to underestimation of the magnitude of deviation from the real birth weight. To remedy for this bias, the absolute value of the percent error was taken as a measure of accuracy in addition to the percent error.

The percent of accurate weight estimation was reported; estimation was considered accurate if its percent error fell within a range of $\pm 10 \%$. The validity of fetal estimation was assessed using intraclass correlation with absolute agreement.

To assess the effect of maternal and fetal factors on fetal weight estimation, percent of accurate estimation was compared using the Chi-Square test for categorical variables (rupture of membrane, presence of contractions, hypertension and otters). The Fisher's exact test was also used for categorical variables when the expected cell count was less than five. The test of means (t-test) was used for continuous variables such as gestational age, maternal weight gain, maternal body mass index (BMI) and others. Data analysis was performed using SPSS version 18.

An Intraclass correlation coefficient of 0.75 was set as the minimum required value to have an agreement between the true and estimated method of fetal weight. Accordingly, a minimum sample size of 166 patients was required to get detect with a power of $80 \%$ an Intraclass correlation of 0.8 with a 0.1 confidence interval width. Alpha level was set at 5\%. The study ended upon reaching the minimum sample required.

\section{Results}

This study included 166 women. Population demographics is shown in Table 1 . The mean \pm standard deviation for body mass index, maternal weight gain, birth weight and gestational age was $28.03 \pm 4.39 \mathrm{~kg} / \mathrm{m}^{2}, 12.9 \pm 4.3 \mathrm{~kg}$, $3246 \pm 362 \mathrm{~g}$, and $38.70 \pm 1.21$ weeks respectively. Boys and girls were equally distributed across the sample (84 girls and 82 boys) and 53\% were night deliveries. Some

Table 1 Demographics and clinical characteristics of women giving birth at a University Hospital in Beirut November 2010-March 2011

\begin{tabular}{|c|c|c|}
\hline & $\mathrm{N}$ & $\%$ \\
\hline \multicolumn{3}{|l|}{ Hypertension } \\
\hline Hypertensive & 3 & $1.8 \%$ \\
\hline Not Hypertensive & 163 & $98.2 \%$ \\
\hline \multicolumn{3}{|l|}{ Rupture of membrane } \\
\hline Membrane ruptured & 28 & $16.9 \%$ \\
\hline Membrane not ruptured & 138 & $83.1 \%$ \\
\hline \multicolumn{3}{|l|}{ Presence of contractions } \\
\hline Contractions present & 68 & $41.0 \%$ \\
\hline Contractions absent & 98 & $59.0 \%$ \\
\hline \multicolumn{3}{|l|}{ Gender of neonate } \\
\hline Female & 84 & $50.6 \%$ \\
\hline Male & 82 & $49.4 \%$ \\
\hline \multicolumn{3}{|l|}{ Shift of delivery } \\
\hline Night & 88 & $53.0 \%$ \\
\hline Day & 88 & $47.0 \%$ \\
\hline \multicolumn{3}{|l|}{ Accuracy of weight estimation } \\
\hline Correct estimation $^{a}$ & 105 & $63.3 \%$ \\
\hline \multirow[t]{2}{*}{ Missed estimation } & 61 & $36.7 \%$ \\
\hline & Mean (SD) & Range \\
\hline Body Mass Index & $28.03(4.39)$ & $19.6-46.3$ \\
\hline Maternal Weight Gain (Kg) & $12.93(4.30)$ & $4-35$ \\
\hline Birth Weight (gm) & $3246(362)$ & $2280-4406$ \\
\hline Gestational Age & $38.70(1.21)$ & $35.2-42$ \\
\hline
\end{tabular}

${ }^{a}$ Correct estimations of fetal weight are defined as estimation with percent error within an interval of $10 \%$ 
patients were admitted for contractions that were felt by the patient but were not detected by the monitoring, along with cervical modification. Estimated fetal weights that were considered as correct (within the range of $10 \%$ ) represent $63 \%$ of the sample.

Table 2 shows the various types of measures of difference between the estimated fetal weight and the real birth weight. The mean percent error was $-1.8 \%$ with a standard deviation of $10.7 \%$ while the mean weight difference was $-84.3 \mathrm{~g}$ with a standard deviation of $353.7 \mathrm{~g}$. The negative sign of the mean percent error and the mean weight difference indicates a certain degree of weight underestimation by the midwives in general. This finding is more evident in Table 3 that describes the percentiles distribution of the percent error and weight differences. The median percent error was $-2.6 \%$ and the median weight difference between estimated and real birth weight was $-85 \mathrm{~g}$, which means that more than half of the fetuses had their birth weight underestimated. Table 4 shows that estimations performed by the midwives had less than desirable agreement with the real birth weight; the Intraclass correlation coefficient was 0.573 with a $95 \%$ confidence interval of $0.42-0.69$.

Table 5 shows that the majority of maternal and fetal factors did not affect the accuracy of fetal weight estimation. The only factor involved was the birth weight group where all fetuses weighting more than 4000 g except one did not have correct weight estimation. Additionally, Fig. 1 shows that the birth weights of this group of neonates were mostly underestimated with a percent error less than minus10\%. There was however few babies in this sub - group and this would probably limit the interpretation of results.

In the span of 6 months, systematic error decreased from about $9 \%$ during the first 4 months to about $6 \%$ during the last 2 months. However, statistical analysis of these data could not demonstrate a significant difference $(p=0.496)$.

Table 2 Means, standard deviation and range of weight difference, absolute weight difference, percent error and absolute percent error for weight estimates performed by midwives at a University Hospital in Beirut

\begin{tabular}{lll}
\hline & Mean (SD) & Range \\
\hline Weight difference $(\mathrm{gm})$ & $-84.3(353.7)$ & $-1110-850$ \\
Absolute weight difference (gm) & $280.4(230.5)$ & $0-1110$ \\
Percent error & $-1.8(10.7)$ & $-28-30.9$ \\
Absolute percent error & $8.5(6.7)$ & $0-30.9$
\end{tabular}

Weight difference is defined as estimated weight-Birth weight, Absolute weight difference is the absolute value of the weight difference. Percentage error is defined as (Estimated weight-Birth weight)*100/Birth Weight. Absolute percent error is the absolute value of the percent error

\section{Discussion}

Midwives represent key players in obstetrics. They sometimes have to rely on manual palpation for weight estimation and this certainly contributes to the subsequent management of labor. Sonographic estimation of fetal weight has also been widely used with a significant correlation between the neonate's estimated and actual weight [10-12]. Nevertheless, fetal weight estimation based on palpation and clinical data is still a valid and reliable method [13-15]. Based on recent studies, clinical methods of fetal weight estimation compared favorably with sonographic estimation [13-16].

Clinical estimation of fetal weight correlated with birth weight, with an average margin of error around $8.6 \%$. The percentage of cases in which the estimated weight is within the range of $\pm 10 \%$ of the actual weight is around $63 \%$. These results are consistent with the results of several studies that found margins of error between 9 and $10 \%$, and percentages of estimated weight contained in a range of $\pm 10 \%$ between 49 and $71 \%$, depending on the fetal weight [13-17].

All patients in the study were at least at 35 weeks on the day of admission, aiming to have a homogeneous group. The time interval between clinical estimation and birth was very short for the 166 patients, which limited the effect of fetal growth on the difference between the estimated and the actual birth weight. The simplest estimation technique was the bimanual abdominal palpation (Leopold-Pavlik method). The accuracy of this clinical estimation is highly variable according to different authors and requires a certain degree of expertise [14, 17, 18], but it remains comparable to that of a sonographic estimation of fetal weight. Sherman et al. showed that the clinical estimation is more accurate than ultrasound in a group of birth weight between 2500 and $4000 \mathrm{~g}$ [13]. Another report confirmed this finding but only for babies less than $2500 \mathrm{~g}$ and between 2500 and $4000 \mathrm{~g}$ [16]. In addition, Hendrix et al. have demonstrated a higher accuracy of the clinical method, whatever the fetal weight [17]. Our study showed a significant correlation between the accuracy of the clinical method and the fetal weight at birth, with a systematic error which increases with fetal weight; it almost reached statistical significance $(p=0.053)$ despite the small sample size. However, the weight of macrosomic fetuses tended to be underestimated [9].

Few authors have investigated the factors that could interfere with the clinical estimation of term fetal weight. Fox et al. have shown that a maternal BMI greater than or equal to 30 significantly reduces the percentage of cases in which the estimated weight is within the range of $\pm 10 \%$ of the actual weight [19]. This finding was not confirmed in our 
Table 3 Percentiles of weight difference, absolute weight difference, parcentage error and absolute percentage error for weight estimates performed by midwives at a University Hospital in Beirut

\begin{tabular}{|c|c|c|c|c|c|c|c|}
\hline & \multicolumn{7}{|c|}{ Percentiles } \\
\hline & 5 th & 10th & 25th & 50th & 75th & 90th & 95th \\
\hline Weight difference (gm) & -673 & -533 & -330 & -85 & 151 & 353 & 506 \\
\hline Absolute weight difference & 13.5 & 38.8 & 100 & 222.5 & 390 & 593 & 720 \\
\hline Percent error & $-17.9 \%$ & $-14.3 \%$ & $-9.6 \%$ & $-2.6 \%$ & $5.1 \%$ & $12.8 \%$ & $18.0 \%$ \\
\hline Absolute percent error & $0.4 \%$ & $1.2 \%$ & $3.1 \%$ & $7.1 \%$ & $12.7 \%$ & $17.9 \%$ & $22.5 \%$ \\
\hline
\end{tabular}

Weight difference is defined as estimated weight-Birth weight, Absolute weight difference is the absolute value of the weight difference. Percent error is defined as (Estimated weight-Birth weight)*100/Birth Weight. Absolute percent error is the absolute value of the percent error

study. Ben-Aroya et al. have shown that there is a statistically significant difference between clinical weight estimations depending on the daytime or nighttime shift but we failed to find such a difference [20]. The accuracy of the clinical estimations was demonstrated to be affected only by the neonate's birth weight where the systematic error was negative, which means that the higher the fetal weight, the more it is underestimated. This could raise some questions about the usefulness of such an estimation, as macrosomia would be theoretically the desired indication for fetal weight estimation before birth. No relationship of the accuracy of the clinical method with the other factors has been found. Fundal height was reported as useful to estimate fetal weight and predict dystocia in term patients in labor [21].

In a study by Levin et al. experience didn't seem to have an impact on clinical fetal weight estimation [22]. However, sharpening the skills of midwives in fetal weight estimation by the clinical method seems to be one of the key elements in the training of midwives. Evolution over time of the accuracy of estimations of fetal weight represents a new aspect of this subject that has been scarcely evaluated in other studies. This is an important variable that could have some impact on training programs for residents and midwives. Despite the fact that the margin of error has a tendency to decrease, change over time is considered non-significant; a larger number of patients may help in reaching a statistically significant increase in estimation accuracy over time. The introduction of a log book of clinical estimation of fetal weight could be interesting to include in a teaching program. Ultrasound estimation by midwives seems to be promising [23].

Table 4 Intraclass correlation coefficients to assess validity of estimated fetal weight by midwives compared to fetal birth weight

\begin{tabular}{lcc}
\hline $\begin{array}{l}\text { Intraclass correlation } \\
\text { coeficient }\end{array}$ & \multicolumn{2}{l}{$95 \%$ Confidence interval } \\
\cline { 2 - 3 } & Lower & Upper \\
\hline 0.573 & 0.419 & 0.686 \\
\hline
\end{tabular}

Table 5 Effect of demographics and clinical factors on the accuracy of fetal weight estimation

\begin{tabular}{|c|c|c|c|c|c|}
\hline & \multicolumn{2}{|c|}{$\begin{array}{l}\text { Correct } \\
\text { estimation }\end{array}$} & \multicolumn{2}{|c|}{$\begin{array}{l}\text { Missed } \\
\text { estimation }\end{array}$} & \multirow[b]{2}{*}{$P$-Value } \\
\hline & $\mathrm{N}$ & $\%$ & N & $\%$ & \\
\hline \multicolumn{6}{|l|}{ Rupture of membrane } \\
\hline Membrane ruptured & 19 & $67.9 \%$ & 9 & $32.1 \%$ & 0.58 \\
\hline Membrane not ruptured & 86 & $62.3 \%$ & 52 & $37.7 \%$ & \\
\hline \multicolumn{6}{|l|}{ Gender of Neonate } \\
\hline Female & 58 & $69.0 \%$ & 26 & $31.0 \%$ & \\
\hline Male & 47 & $57.3 \%$ & 35 & $42.7 \%$ & 0.12 \\
\hline \multicolumn{6}{|l|}{ Presence of contractions } \\
\hline Contractions present & 45 & $66.2 \%$ & 23 & $33.8 \%$ & 0.52 \\
\hline Contractions absent & 60 & $61.2 \%$ & 38 & $38.8 \%$ & \\
\hline \multicolumn{6}{|l|}{ Shift of delivery } \\
\hline Night & 58 & $65.9 \%$ & 30 & $34.1 \%$ & \\
\hline Day & 47 & $60.3 \%$ & 31 & $39.7 \%$ & 0.45 \\
\hline
\end{tabular}

Diabetes

$\begin{array}{llllll}\text { Diabetic } & 10 & 66.7 \% & 5 & 33.3 \% & 0.77\end{array}$

$\begin{array}{lllll}\text { Not Diabetic } & 95 & 62.9 \% & 56 & 37.1 \%\end{array}$

Hypertension

$\begin{array}{llllll}\text { Hypertensive } & 2 & 66.7 \% & 1 & 33.3 \% & 0.70\end{array}$

$\begin{array}{lllll}\text { Not Hypertensive } & 103 & 63.2 \% & 60 & 36.8 \%\end{array}$

Birth weight group

$\begin{array}{llllll}<3000 & 26 & 63.4 \% & 15 & 36.6 \% & \\ 3000-4000 & 78 & 65.5 \% & 41 & 34.5 \% & \\ >4000 & 1 & 16.7 \% & 5 & 83.3 \% & 0.053 \\ \text { Body Mass Index: Mean (SD) } & 28.04(4.82) & 28.02(3.6) & 0.972 \\ \text { Maternal Weight Gain: Mean (SD) } & 12.65(4.59) & 13.42(3.75) & 0.269 \\ \text { Parity: Mean (SD) } & 0.50(0.70) & 0.62(0.78) & 0.314 \\ \text { Gestational Age: Mean (SD) } & 38.66(1.24) & 38.79(1.18) & 0.529\end{array}$

Effect is measured as \% difference in correct estimation across categories of nominal variables and as means difference for numeric continuous variables. A correct estimation is defined as a fetal weight estimation that falls within a $10 \%$ interval from the real birth weight 


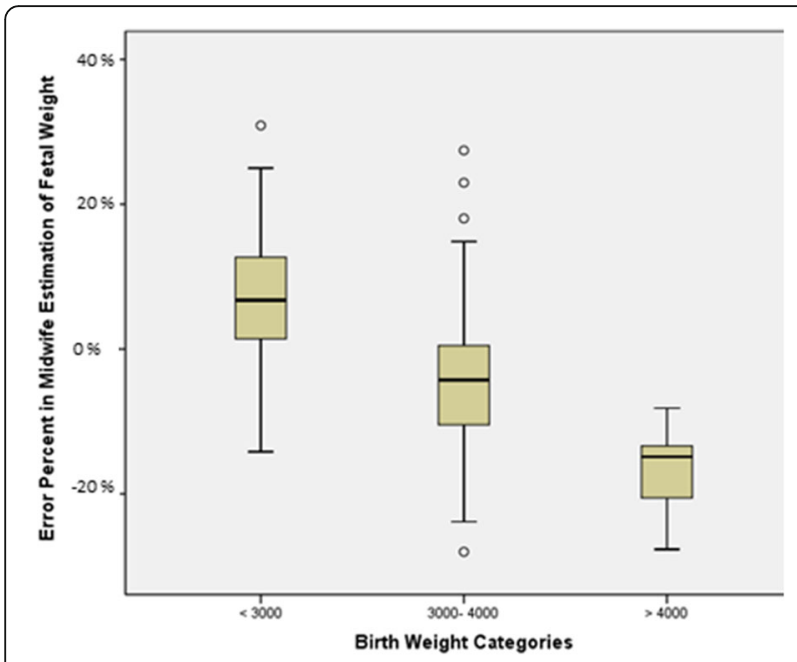

Fig. 1 Box plot of quartiles of percent error in fetal weight estimation. The bold horizontal lines inside the boxes represent the medians. The lower and upper edge of the boxes represent the $25^{\text {th }}$ and $75^{\text {th }}$ percentiles respectively

The major limitation of this study is the small number of enrolled patients thus reducing the strength of the study. Another limitation is the fact that the study did not assess the potential benefit that could be given to the patient in response to this clinical estimation, such as a decrease in fetal or maternal morbidity and mortality. A subsequent study addressing these two issues would possibly have a great impact on the recommendations for the obstetrical management.

\section{Conclusions}

Most of the maternal and fetal factors did not affect the accuracy of fetal weight estimation, except for macrosomia where midwives tended to underestimate the weight. Improvement of the estimation over time is seen after 4 months but was not statistically significant. Larger trials are needed to evaluate how to improve this estimation in university teaching programs. This could also have an impact on rural medical centers with limited resources, as well as on parturients with limited prenatal care.

\section{Synopsis}

Macrosomia influences prenatal fetal weight estimation.

\section{Abbreviation}

BMl: Body mass index

\section{Acknowledgements}

We would like to thank the midwives team for their commitment to this study. We also would like to thank Mr Ahmad Abdallah for his help in reviewing the results of the study.

\section{Funding}

No funding was obtained for this study.

\section{Availability of data and materials}

The datasets generated and analyzed during the current study are not publicly available due to restriction of our institution but are available from the corresponding author on reasonable request.

\section{Authors' contributions}

AK and CA participated in the design of the study and in writing the manuscript. HK retrieved information about weight assessment. NA was responsible for coordinating with the midwives included in the study and participated in data collection. EA participated in administrative issues and in reviewing the manuscript. CA and RA helped in correcting and reviewing statistics of the study. CA, RA and AK: reviewing and finalizing the study for submission. All authors read and approved the final manuscript.

\section{Competing interests}

All authors declare no competing interests.

\section{Consent for publication}

Not applicable.

\section{Ethics approval and consent to participate}

This study was submitted to our institutional ethics committee (Saint Joseph University ethics committee), approved and registered as CEHDF-919. Oral consent was mandatory for all participating patients after they had read the objective and protocol of the study. The patients were free to participate or not without any coercion. This was done in accordance with our institution's regulation as weight estimation was just recorded and did not have any impact on the course of labor, nor maternal or fetal outcome. Our ethics committee gave approval to this protocol. The midwives gave an oral consent and were enthusiastic to participate to this study.

\section{Author details}

'Ob-Gyn Department, St Joseph University, Adib Ishac St, Achrafie, Beirut, Lebanon. ${ }^{2}$ RM, Hotel-Dieu de France University Hospital, Beirut, Lebanon.

${ }^{3}$ The Johns Hopkins Hospital, General Surgery, Baltimore, MD, USA. ${ }^{4}$ Johnston Willis Hospital, Obstetrics and Gynecology, Richmond, VA, USA.

Received: 14 September 2015 Accepted: 31 January 2017

Published online: 08 February 2017

\section{References}

1. ACOG Committee on Practice Bulletins-Gynecology, The American College of Obstetrician and Gynecologists. ACOG practice bulletin clinical management guidelines for obstetrician-gynecologists. Number 40, November 2002. Obstet Gynecol. 2002;100:1045.

2. McIntire DD, Bloom SL, Casey BM, Leveno KJ. Birth weight in relation to morbidity and mortality among newborn infants. N Engl J Med. 1999:340: 1234

3. Bernstein IM, Horbar JD, Badger GJ, et al. Morbidity and mortality among very-low-birth-weight neonates with intrauterine growth restriction. The Vermont Oxford Network. Am J Obstet Gynecol. 2000;182:198.

4. Ju H, Chadha Y, Donovan T, O'Rourke P. Fetal macrosomia and pregnancy outcomes. Aust N Z J Obstet Gynaecol. 2009;49:504.

5. Mulik V, UshaKiran TS, Bethal J, Bhal PS. The outcome of macrosomic fetuses in a low risk primigravid population. Int J Gynaecol Obstet. 2003;80(1):15-22.

6. Dildy GA, Clark SL. Shoulder dystocia: risk identification. Clin Obstet Gynecol. 2000;43:265.

7. Overland EA, Spydslaug A, Nielsen CS, Eskild A. Risk of shoulder dystocia in second delivery: does a history of shoulder dystocia matter? Am J Obstet Gynecol. 2009;200:506.e1.

8. McFarland LV, Raskin M, Daling JR, Benedetti TJ. Erb/Duchenne's palsy: a consequence of fetal macrosomia and method of delivery. Obstet Gynecol. 1986;68(6):784-8.

9. Goetzinger K, Odibo A, Shanks A, Roehl K, Cahill A. Clinical accuracy of estimated fetal weight in term pregnancies in a teaching hospital. J Matern Fetal Neonatal Med. 2014;27(1):89-93.

10. Merz E. Fetal weight estimation. Merz E (2nd ed), ultrasound in obstetrics and gynecology :thieme. 2005. p. 163-7.

11. Chitra Y. The sonographic criteria for estimating fetal weight. Realities in obstetrics and gynecology. №. 123 - book 1. 2007. 
12. Dudley NJ. A systematic review of the ultrasound estimation of fetal weight. Ultrasound Obstet Gynecol. 2005;25(1):80-9.

13. Sherman DJ, Arieli S, Tovbin J, Siegel G, Caspi E, Bukovsky I. A comparison of clinical and ultrasonic estimation of fetal weight. Obstet Gynecol. 1998; 91(2):212-7.

14. Noumi G, Collado-Khoury F, Bombard A, Julliard K, Weiner Z. Clinical and sonographic estimation of fetal weight performed during labor by residents. Am J Obstet Gynecol. 2005;192(5):1407-9.

15. Torloni MR, Sass N, Sato JL, Renzi AC, Fukuyama M, de Lucca Rubia P. Clinical formulas, mother's opinion and ultrasound in predicting birth weight. Sao Paulo Med J. 2008;126(3):145-9.

16. Belete W, Gaym A. Clinical estimation of fetal weight in low resource settings: comparison of Johnson's formula and the palpation method. Ethiop Med J. 2008;46(1):37-46.

17. Peregrine $E, O^{\prime} B r i e n ~ P$, Jauniaux E. Clinical and ultrasound estimation of birth weight prior to induction of labor at term. Ultrasound Obstet Gynecol. 2007:29(3):304-9.

18. Hendrix NW, Grady CS, Chauhan SP. Clinical vs. sonographic estimate of birth weight in term parturients. A randomized clinical trial. J Reprod Med. 2000;45(4):317-22.

19. Fox NS, Bhavsar V, Saltzman DH, Rebarber A, Chasen ST. Influence of maternal body mass index on the clinical estimation of fetal weight in term pregnancies. Obstet Gynecol. 2009;113(3):641-5.

20. Ben-Aroya Z, Segal D, Hagar A, Hallak M, Friger M, Katz M, Mazor M. Effect of OB/GYN residents' fatigue and training level on the accuracy of fetal weight estimation. Fetal Diagn Ther. 2002;17(3):177-81.

21. Buchmann E, Tlal K. A simple clinical formula for predicting fetal weight in labour at term-derivation and validation. S Afr Med J. 2009;99(6):457-60

22. Levin I, Gamzu R, Buchman V, Skornick Rapaport A, Pauzner D, Lessing JB, et al. Clinical estimation of fetal weight: is accuracy acquired with professional experience? Fetal Diagn Ther. 2011;29(4):321-4.

23. Mattsson N, Rosendahl H, Luukkaala T. Good accuracy of ultrasound estimations of fetal weight performed by midwives. Acta Obstet Gynecol Scand. 2007;86(6):688-92.

\section{Submit your next manuscript to BioMed Central and we will help you at every step:}

- We accept pre-submission inquiries

- Our selector tool helps you to find the most relevant journal

- We provide round the clock customer support

- Convenient online submission

- Thorough peer review

- Inclusion in PubMed and all major indexing services

- Maximum visibility for your research

Submit your manuscript at www.biomedcentral.com/submit

) Biomed Central 